\title{
Território da Cidadania do Médio Alto Uruguai: sobre qual pobreza estamos falando?
}

\author{
Upper Middle Uruguay Citizenship Territory: what poverty are we talking about?
}

Jeferson Tonin ${ }^{1}$

\begin{abstract}
Resumo
O objetivo deste trabalho é analisar a concepção de pobreza no Programa Territórios da Cidadania no âmbito do Território Médio Alto Médio Uruguai. Essa questão emerge da dificuldade em compreender o fenômeno da pobreza, haja vista a complexidade que lhe é intrínseca e as múltiplas faces que pode englobar. Entender como a pobreza é concebida é fundamental na medida em que as ações decorrentes do programa são construídas justamente a partir desse entendimento. A análise é focada em três momentos: i) durante a formulação do programa; ii) durante a elaboração do plano territorial, e; iii) durante a execução das ações. Para isso, são analisados materiais que descrevem e orientam todas as ações, como o decreto de criação, o plano elaborado pelo território e o conjunto das ações executadas. Os resultados deste artigo demonstram que o termo pobreza está associado ao termo desigualdade social e que, embora o programa busque inicialmente contemplar outras dimensões, a pobreza em si é compreendida desde o início a partir de uma esfera econômica enquanto o termo desigualdade precisa ser incluído para contemplar as demais esferas de atuação.
\end{abstract}

Palavras-chave: PTC. Políticas Territoriais. Pobreza Rural.

\begin{abstract}
This study aims at analyzing the concept of poverty in the "Territories of the Citizenship Program" in the Upper Middle Uruguay Territory. This issue emerges from the difficulty in understanding the poverty phenomenon, because of its complexity, which is intrinsic, and its multiple faces. Understanding how poverty is conceived is fundamental as far as the actions of the program are built precisely from that understanding. This analysis focuses on three points: i) during the formulation of the program; ii) during the preparation of the territorial plan, and; iii) during the execution of the actions. Regarding this, we analyze materials that describe and guide all actions, such as the decree of creation, the territory development plan, and the set of performed activities. The results of this article demonstrate that the term poverty is related to the term social inequality and, although the program initially pursuits to contemplate other aspects, poverty itself is understood since the beginning, starting from an economic sphere, whereas the term inequality needs to be included to address other fields of activity.
\end{abstract}

Keywords: PTC. Territorial Policies. Rural Poverty.

\footnotetext{
1 Professor do Instituto de Educação, Agricultura e Ambiente, Universidade Federal do Amazonas. E-mail: jeferson.tonin@hotmail.com
} 


\section{Introdução}

O Programa Territórios da Cidadania (PTC) foi institucionalizado no ano de 2008 com a premissa de basilar de combate à desigualdade social e à pobreza rural. A abordagem operacional com foco nos territórios foi herdada de seu antecessor, o Programa Nacional de Desenvolvimento Sustentável dos Territórios Rurais (PRONAT), criado em 2003. Com o acompanhamento dos Territórios Rurais - vinculados ao PRONAT - ficou claro para os representantes do Estado e da sociedade civil que alguns possuíam altos índices de pobreza rural, conflitos por terra e baixo Índice de Desenvolvimento Humano (IDH), justificando, portanto, a necessidade de criar um programa mais amplo e que se propunha ir além das inclusão produtiva. Assim sendo, a criação do PTC tem como objetivo central "promover e acelerar a superação da pobreza e das desigualdades sociais, inclusive de gênero, raça e etnia” (BRASIL, 2008).

O tema da pobreza é amplamente abordado, direta ou indiretamente, na literatura acadêmica (FURTADO, 2007; PIKETTY, 2014; KAGEYAMA e HOFFMANN, 2006; SEN, 1999), não obstante, foi incorporado ao debate sobre políticas públicas apenas recentemente, uma vez que a própria existência de uma agenda social robusta é, também, algo contemporâneo no universo brasileiro. Após uma década de sua implementação, uma série de estudos tem sido realizada sobre o Programa Territórios da Cidadania, quer seja na esfera de seu aspecto metodológico (MALUFF, 2013; BONNAL et al., 2011; FAVARETTO, 2015), quer seja com o intuito de fazer uma análise da política pública (DELGADO e LEITE, 2015; GRISA, 2013) ou mesmo para estudar aspectos específicos sobre a pobreza (MATTEI e TECCHIO, 2013; BONNAL, 2013).

Nos trabalhos que abordam o tema da pobreza em políticas públicas, uma das principais discussões estabelecidas diz respeito ao modo como é concebida a pobreza rural, englobando desde algumas perspectivas unidimensionais até outras que consideram a pobreza como algo necessariamente multifacetado. Seja como for, essa discussão torna-se ainda mais complexas por conta da gestão social participativa, que também é uma premissa desde o PRONAT (BRASIL, 2008). Isto é, há uma importante parcela de contribuição da sociedade civil organizada na definição dos rumos da ação pública, desde a delimitação dos principais eixos de atuação do território (durante a elaboração do Plano Territorial de Desenvolvimento Rural Sustentável - PTDRS) até a própria gestão dos recursos. Significa dizer, em outras palavras, que a noção de pobreza rural pode variar no percurso que compreende a formulação de uma política pública até sua execução de fato, dentro dos limites estabelecidos pelo programa. 
Nesse sentido, o objetivo deste trabalho é analisar a concepção da pobreza no Programa Território da Cidadania no âmbito do Território do Médio Alto Médio Uruguai. Trata-se de identificar o que efetivamente considera-se pobreza em três momentos do PTC: i) durante sua formulação; ii) durante a elaboração do PTDRS, e; iii) durante a execução das ações de fato. Para isso, o artigo está divido em quatro partes. Inicialmente, são apresentadas as principais condições que possibilitaram a criação de um território da cidadania no Médio Alto Uruguai. Posteriormente, abordam-se as principais perspectivas teóricas que se propõem a construir a pobreza como um objeto de estudo, com o intuito de discutir a diversidade de interpretações. A terceira parte contempla as opções metodológicas utilizada neste estudo e, finalmente, são discutidas as concepções teóricas sobre pobreza que nortearam o PTC no âmbito do Território Médio Alto Uruguai em seus três momentos: formulação, planejamento e execução.

É importante destacar que este trabalho não tem a pretensão de realizar uma análise do programa no sentido de identificar em que medida seus objetivos foram cumpridos ou não, pelo contrário, este é um esforço de elucidar como a pobreza tem sido entendida nas diferentes camadas de um programa e de que forma isso reflete em sua execução. Análise de política pública, portanto, não se enquadra no escopo desse trabalho.

\section{A construção de um Território da Cidadania no Médio Alto Uruguai}

Com a institucionalização do Programa Territórios da Cidadania, estabeleceram-se alguns critérios para que um território rural, já incluído no PRONAT, fosse transformado em um território da cidadania. Dentre os critérios, destacam-se a) baixo IDH; b) alta concentração de agricultores familiares e assentamentos da Reforma Agrária; c) alta concentração de populações quilombolas e indígenas; c) alto número de beneficiários do Programa Bolsa Família; d) grande número de municípios com baixo dinamismo econômico; e) maior organização social; f) pelo menos um território por estado da federação (BRASIL, 2008).

Considerando estas condições, convém fazer uma breve digressão para retomar o contexto e os motivos que permitiram a efetivação de um território da cidadania na região do Médio Alto Uruguai. A ocupação do extremo norte do Rio Grande do Sul, do ponto de vista da formação de colônias agrícolas ${ }^{2}$, é consideravelmente recente se comparada às demais regiões do Rio Grande do

\footnotetext{
${ }^{2}$ Nesse caso, enfatiza-se a ocupação desse território por europeus não-ibéricos, que ocorreu, grosso modo, na metade norte do Rio Grande do Sul a partir da formação de colônias agrícolas, onde inicialmente produzia-se para o autoconsumo e, posteriormente, para a venda de excedentes.
} 
Sul, haja vista que ocorreu no final da primeira metade do século XX. Trata-se, portanto, de uma das últimas regiões do estado a receber fluxos migratórios nessas condições (FRANTZ e SILVA NETO, 2015). Ademais, é necessário destacar que, por ser um processo tardio, não foi um movimento conduzido pelo Estado ou mesmo por entidades privadas organizadas, tratando-se, então, de uma ocupação desordenada (RODRIGUES, 2009) e sem o apoio necessário, tanto para questões produtivas como para questões sociais e ambientais, por exemplo.

Somam-se a essas características outros elementos, como a presença de condições edáficas desfavoráveis (solos rasos, pedregosos e de topografia ondulada), a marginalidade geográfica desta região (à luz dos grandes centros urbanos, ou seja, dos principais mercados) e a fragilidade econômica, que é característica das famílias que aqui chegaram (GAZOLLA, 2012; BOSCARDIN, 2017). Todos estes fatores foram fundamentais para que as dinâmicas socioeconômicas locais fossam construídas a partir de condições desfavoráveis e profundamente distintas, tornando a desigualdade social algo muito presente no contexto agrário local, conforme apontam algumas pesquisas (OLCZEVSKI, 2007; LIMA et al., 2020).

Por conta da dificuldade de reprodução social de boa parte dos agricultores, os anos 1990 foram palco de projetos com vistas à diversificação produtiva, nos quais a fruticultura e a olericultura foram as principais atividades fomentadas. De acordo com um estudo realizado por Gazolla (2012) na região de Frederico Westphalen, foi também neste período que as agroindústrias familiares rurais começam a adquirira maior importância nessa porção do estado gaúcho, principalmente pela sua capacidade de agregar valor aos produtos primários. Não obstante, estas ações não foram suficientes para alterar estruturalmente o quadro de descapitalização em que se encontrava boa parte dos agricultores familiares (LIMA et al., 2020; TONIN et al., 2018). À essa situação, acrescenta-se ainda o fato de que a década de 1990 é reconhecidamente um período de diminuição da ação do Estado, em que as ideários neoliberais marcaram as opções político-econômicas no Brasil e agravaram ainda mais o contexto social da agricultura familiar (DELGADO, 2005; GRISA e SCHNEIDER, 2015).

Outros fatores também foram fundamentais, como o baixo IDH, que, à época, era o menor dentre os territórios do Rio Grande do Sul e contribuiu neste processo (GUBERT et al., 2018). Vale ressaltar, também, a intensa capacidade de organização social. Conforme dados do Atlas Socioeconômico do Rio Grande do Sul (2019), há terras indígenas ${ }^{3}$, demarcadas ou não, em pelo menos nove municípios do território. Além disso, em paralelo a institucionalização do Território da Cidadania do Médio Alto Uruguai (TCMAU), as representações da sociedade civil articularam-se

\footnotetext{
3 Destacam-se as nações Guaraní e Kaingang.
} 
para a criação de uma Agência de Desenvolvimento do Médio Alto Uruguai (ADMAU), cuja composição envolve cooperativas, sindicatos, instituições de ensino, secretarias municipais, Emater e demais entidades locais.

A partir desta configuração geral, percebe-se que a região atendia aos critérios supracitados para sua incorporação no PTC e, assim sendo, no ano de 2010 o Território do Médio Alto Uruguai foi reconhecido como um Território da Cidadania, englobando um total de 34 municípios.

\section{A pobreza como objeto de estudo}

Identificar uma situação de pobreza, empiricamente, pode ser uma tarefa consideravelmente simples, sobretudo quando se compara diferentes grupos sociais, ocorre que entender a pobreza como objeto de estudo requer certa abstração e um aporte teórico capaz de sustentar uma análise (KUHN, 2008). Não é fácil, porém, construir uma base teórico-metodológica que consiga contemplar toda a complexidade de um fenômeno tão amplo, multifacetado e heterogêneo, principalmente estabelecendo interfaces com a dimensão rural.

Mesmo assim, muitos pesquisadores se dedicam a investigar o tema, o que gera uma grande diversidade de interpretações, por vezes contraditórias, para o mesmo fato. Neste tópico, sem o intuito de realizar um resgate exaustivo sobre o estado da arte deste tema, será realizado um esforço de apresentar uma síntese das diferentes concepções no desígnio de elucidar tamanha multiplicidade de abordagens. Essa discussão não é recente, mas continua atual, de modo que estas definições serão importantes para, posteriormente, identificar de que modo determinada ação pública está "atacando" a pobreza rural. Antes de analisar a eficiência ou a eficácia de uma política pública, é preciso saber quais perguntas devem ser feitas, ou seja, é necessário compreender como efetivamente ela concebe o problema.

Propondo-se a pensar a pobreza, certamente a dimensão econômica é a mais utilizada. Nesse sentido, utiliza-se a renda para estabelecer linhas abaixo das quais os indivíduos são considerados em situação de pobreza ou extrema pobreza. Nestes casos em que a pobreza é abordada à luz de uma perspectiva unidimensional - a renda per capita -, os autores consideram que é preciso estimar a renda necessária para que cada cidadão seja capaz de ter acesso a determinados bens considerados essenciais. Por exemplo, em uma das abordagens "são definidos como pobres aqueles que não dispõem dos meios para atendar as necessidades de alimentação [...], nem as demais necessidades de vestuários, educação, despesas pessoais, habitação, etc.” (ROCHA, 1995, p. 2). O Banco Mundial também deposita grande importância no aspecto econômico para identificação da extrema pobreza. 
No relatório anual de 2018, a extrema pobreza é definida utilizando unicamente valor monetário, cuja linha de delimitação é traçada em US\$ 1,90 por dia (BANCO MUNDIAL, 2018).

Essa é uma abordagem muito utilizada, principalmente na formulação de políticas públicas, dada sua amplitude, mas também na delimitação da população a ser considerada em estudos acadêmicos. Não obstante, compreender a pobreza unicamente sob a ótica da renda tem gerado uma série de críticas por quem considera a pobreza como um fenômeno necessariamente multifacetado, englobando, a depender da abordagem, questões como saúde, saneamento, educação, longevidade, discriminação etc. Pode-se dizer, inclusive, que há certo acordo na academia sobre a necessidade de ampliar o espectro de análise da pobreza para além da renda, a questão central que vem norteando as discussões é sempre qual o parâmetro utilizar e de que forma pode ser operacionalizado nos mais diversos contextos e escalas (BARROS et al., 2006). Na década de 1950 as Nações Unidas já “expressavam a necessidade de combinar padrões relativos e medidas variadas de saúde, habitação, vestuário, habitação, a fim de tornar possíveis as comparações intra e internacionais de pobreza" (KAGEYAMA e HOFFMANN, 2006, p. 86).

Considerando essa necessidade, um grande esforço tem sido realizado com o objetivo de construir abordagens multidimensionais de pobreza. Uma das propostas mais utilizadas é o Índice de Desenvolvimento Humano (IDH), criado pela Organização das Nações Unidas nos anos 1990. Conforme dados do Programa das Nações Unidas para o Desenvolvimento - PNUD (SOARES et al., 2018), o índice congrega três esferas de análise: saúde, educação e renda. No âmbito da saúde, uma vida longa e saudável é medida pela expectativa de vida. $\mathrm{O}$ aspecto da renda é mensurado pelo padrão de vida e expresso em Renda Nacional Bruta per capita. Por fim, a educação é analisada avaliandose a média de anos de educação de adultos e a expectativa de anos de educação para crianças em idade de começar a vida escolar.

A partir do IDH, criou-se também o Índice de Desenvolvimento Humano Municipal (IDHm), que surge pela necessidade de um indicador que contemple as especificidades brasileiras. A adaptação ocorreu em 2013, mas como englobam as mesmas três dimensões (saúde, educação e renda), foi possível calculá-lo também para os anos anteriores para os quais existiam dados: 1991 e 2000 (PNUD, 2013). O IDHm representou um grande avanço nas análises sobre desenvolvimento humano, visto que engloba mais de 200 indicadores socioeconômicos que auxiliam na apreensão das diferentes dinâmicas municipais.

Como se pode perceber, tanto o IDH como o IDHm não são índices que mensuram diretamente a pobreza, pelo contrário, são índices construídos para avaliar o desenvolvimento humano, o que segue é uma relação inversamente proporcional entre pobreza e desenvolvimento 
humano. Contudo, a Organização das Nações Unidas criou também o Índice de Pobreza Humana (IPH), que, esse sim, elaborado a partir da longevidade, educação e padrão de vida, serve para avaliar a manutenção e a sobrevivência da espécie humana (KUHN, 2008). Mesmo sendo menos utilizado que o IDH e o IDHm em estudos, ele representa um avanço no sentido que concentra maior importância no aspecto da pobreza em si. Pode-se dizer que esse critério avalia a falta destas três dimensões citadas, ou seja, baixa longevidade, pouco acesso à educação e baixa renda.

$\mathrm{Na}$ esteira de trabalhos dedicados a compreender o fenômeno da pobreza como algo multidimensional, é necessário falar sobre a perspectiva proposta por Kageyama e Hoffmann (2006), que dialoga a medida tradicional, baseada na renda, com outros aspectos relacionados ao bem-estar ou desenvolvimentos social. Neste prisma, os autores utilizam os microdados da Pesquisa Nacional por Amostra de Domicílios (PNAD) de 2004 para, juntamente a renda, elaborar previamente categorias para a análise da pobreza. Considera-se uma linha fixada em 50\% do salário mínimo e também a existência de três elementos: água canalizada, banheiro e luz elétrica. As categorias foram construídas obedecendo as seguintes condições: a) extremamente pobres: renda abaixo do nível mínimo e ausência de todos os elementos (água canalizada, banheiro e luz elétrica); b) pobreza tipo I: renda abaixo do nível e presença de pelo menos um elemento; c) pobreza tipo II: renda acima do nível e presença de até dois elementos; e d) não pobres: renda acima do nível e presença de mais que dois elementos.

Estas últimas propostas mencionadas são apenas algumas dentre várias tentativas levadas a cabo por estudiosos que têm o intuito de examinar a pobreza a partir de variáveis que não apenas a renda. Não obstante, é preciso ponderar que qualquer definição prévia das dimensões da pobreza significaria inferir que tais componentes são, indubitavelmente, uma dimensão da pobreza (KUHN, 2008), o que pode ser equivocado. Nesse sentido, a proposta de Amartya Sem propõe, dentre outras coisas, alterar essa lógica e estudar as faces da pobreza através de uma abordagem que não define nem restringe as variáveis consideradas.

Com o intuito de captar ainda mais a complexidade e as muitas facetas da pobreza, muitos autores têm utilizado a noção de capacitações que foi elaborada por Amartya Sen, cuja abordagem acrescenta um aspecto qualitativo nas análises sobre pobreza. Esforçando-se para não aparentar simplista a complexa abordagem das capacitações, convém salientar três conceitos fundamentais: capacitação, intitulamento e funcionamento. $\mathrm{O}$ primeiro conceito diz respeito às possibilidades de uma determinada pessoa, isto é, aquilo que ela pode ou tem condições de fazer. Intitulamento, por sua vez, são os meios necessários para tal e, por fim, funcionamento é a realização, de fato, dos intitulamentos (SEN, 2001). 
Nesse sentido, a pobreza pode ser definida como privação de capacitações. Por exemplo, em estudo sobre a pobreza no Rio Grande do Sul, Kuhn et al (2006) demonstraram que para combater as situações de pobreza é precisa considerar, além da renda, outras dimensões, como a saúde e a educação, o que implica afirmar que uma série de problemas não são solucionados apenas com o incremento de renda. Dentre as variáveis que o estudo considerou, destacam-se o número de médicos, presença de água encanada, acesso à educação, alfabetização e sobrevivência.

As abordagens e teorias mobilizadas neste tópico são importantes para perceber o quão diverso é o universo de análise da pobreza. A concepção de pobreza a ser utilizada na realização de um estudo ou na formulação de uma política pública é uma opção metodológica, todavia, tal opção possui um efeito direto, primeiramente, na delimitação do universo em questão e, em segundo lugar, nos métodos a serem adotados.

\section{Caminhos metodológicos}

A análise sobre a concepção de pobreza que foi utilizada para operacionalizar o Programa Territórios da Cidadania no Médio Alto Uruguai está considerando três diferentes momentos de uma ação pública, a saber, sua formulação, a elaboração do plano de desenvolvimento e as ações executadas. Este tópico visa elucidar estas três esferas do programa e de que forma serão utilizados. Todas as informações foram obtidas de bibliografias, publicações institucionais e dados secundários.

- Análise das diretrizes do programa: O Programa Territórios da Cidadania foi instituído pelo DNN 11503 de 25 de fevereiro de 2008. Em seu texto, estão especificadas, além dos objetivos do programa, as condições necessárias para a criação de um TC e também outros aspectos importantes, como a própria composição do grupo responsável por executar e acompanhar as ações, incluindo uma série de secretarias e ministérios. A partir desta relação, espera-se poder elucidar qual foi a noção de pobreza que orientou a formulação deste programa.

- Análise do Plano Territorial de Desenvolvimento Rural Sustentável - PTDRS: Após a criação de um TC, um dos primeiros passos é a definição das linhas prioritárias de investimento. Esta delimitação, mesmo que passando pela chancela dos ministérios responsáveis, parte de uma construção social participativa com base no entendimento que o território possui sobre o programa e sobre sua própria realidade. Esse modus operandi já era utilizado desde o PRONAT e foi mantido na implementação do PTC. O PTDRS do TCMAU (FLORES e PRESTES, 2010) foi elaborado no ano de 2010 e, dentre outros elementos, contempla 17 eixos aglutinadores, isto é, 17 áreas nas quais os recursos do programa deveriam ser investidos. Em cada um destes eixos aglutinadores, há um 
conjunto de ações específicas que foram pré-estabelecidas. Parte-se do pressuposto que a delimitação destes eixos aglutinadores pode ser utilizada para compreender qual a concepção de pobreza que era compartilhada pelo território, uma vez que é o território o principal responsável por essa construção e servem justamente para balizar as ações a partir das demandas locais.

- Análise das ações executadas: No ano de 2015, a Secretaria de Desenvolvimento Territorial, vinculada ao então Ministério do Desenvolvimento Agrário produziu uma série de publicações com dados dos diferentes territórios rurais e da cidadania que foram implementados até o ano da publicação (MDA, 2015). Esse relatório faz uma síntese de todas as ações voltadas ao território em questão, incluindo entidade proponente, município, objeto da ação, valor e situação atual de cada uma delas. Além disso, há também uma espécie de contextualização do território, explorando variáveis como número de estabelecimentos de agricultores familiares, famílias assentadas, beneficiários do Programa Bolsa Família, Programa de Aquisição de Alimentos, Programa Nacional de Alimentação Escolar e outros dados gerais. De posse destas informações, pretende-se i) estabelecer o perfil principal das ações executadas a partir do ano de $2010^{4}$; e ii) identificar o destino destas ações e relacionar com as características dos principais municípios beneficiados.

A trajetória de um programa não é algo linear e sem arestas, pelo contrário, existe uma série de fatores que influenciam nestas dinâmicas, desde mobilização local até articulação do território e relações de poder, contudo, é possível identificar os grandes movimentos e as grandes tendências dos diferentes momentos de ação como essa.

\section{Afinal, de que pobreza estamos tratando?}

Neste tópico, serão analisadas as diferentes concepções de pobreza durante as três principais etapas desta ação do Estado, a saber, sua formulação, seu planejamento e sua execução.

\section{As diretrizes de um programa de combate à pobreza e às desigualdades}

O decreto que institui o PTC (11.503, de 25 de fevereiro de 2008) não define o que considera pobreza. A primeira análise deste trabalho concentra-se em sua estruturação, considerando o objetivo, os critérios para que um território possa ser considerado um TC e as estratégias pré-definidas no decreto. A começar pelo objetivo central do programa (promover e acelerar a superação da pobreza

\footnotetext{
${ }^{4}$ Ano em que o PTC passa a operar.
} 
e das desigualdades sociais no meio rural $^{5}$, inclusive as de gênero, raça e etnia, por meio de estratégia de desenvolvimento territorial sustentável), não se pode desconsiderar que o termo pobreza está associado à desigualdade, tampouco conceituada. Convém destacar que essa última, pela menção às várias faces da desigualdade, apresenta-se de forma mais ampla e não delimita as dimensões que pretende contemplar. Portanto, a ideia construída nessa lógica é de que há uma diferença conceitual entre pobreza e desigualdade. Não é possível fazer afirmações absolutamente precisas a respeito desse aspecto, mas quando se utiliza a expressão desigualdade para referir-se às diferentes faces que o programa pretende incorporar é porque o termo pobreza parece não suportar essa multidimensionalidade. A partir dessa reflexão, é necessário diferenciar o objetivo dessa análise, a pobreza, de outro objeto igualmente importante, a desigualdade, cujo estudo demandaria um esforço conceitual e analítico que extrapola o escopo desse artigo. Desse modo, o foco recai sobre a pobreza, embora sem desconsiderar a centralidade das desigualdades para o PTC.

Os critérios avaliados para que um território seja considerado um território da cidadania sugerem uma percepção que ultrapassa os limites da esfera econômica. Pelo menos três das seis variáveis mobilizadas confirmam essa tendência, uma vez que territórios com baixo IDH, alto nível de organização social e grande concentração de municípios com baixo IDEB (Índice de Desenvolvimento da Educação Básica) eram considerados prioritários. Isto é, aspectos relacionados a saúde (que estão inclusos no IDH), a educação (incluídos no IDH e no IDEB) e a organização social somam-se à dimensão econômica, mas não são produto desta.

Além disso, as estratégias mencionadas para que os objetivos fossem atingidos fornecem mais elementos para tal compreensão: i) integração de políticas públicas com base no planejamento territorial; ii) ampliação dos mecanismos de participação social na gestão das políticas públicas de interesse do desenvolvimento dos territórios; iii) ampliação da oferta dos programas básicos de cidadania; e iv) inclusão produtiva das populações pobres e dos segmentos sociais mais vulneráveis, tais como trabalhadoras rurais, quilombolas, indígenas e populações tradicionais. Além do aspecto territorial facilmente percebido nessas estratégias, a segunda e a terceira, ao partirem da participação social e da cidadania, evidenciam, novamente, uma preocupação com aspectos que extrapolam uma abordagem estritamente econômica. Não obstante, reitera-se, o fato de que o programa possui

\footnotetext{
${ }^{5}$ Por conta do escopo deste trabalho, furtamo-nos de abordar o tema da ruralidade. Convém destacar apenas que, além de não definir pobreza, o decreto também não define o que considera rural. Sobre isso, há uma interessante e pertinente discussão conduzida por Kuhn (2007) que aponta as limitações de grande parte dos estudos que entendem o rural simplesmente como "não urbano", isto é, sem considerar as característica e as especificidades que o define A autora aponta algumas interfaces entre a questão da ruralidade e da pobreza.
} 
diferentes e importantes frentes de atuação não implica em ampliação o conceito de pobreza, uma vez que o programa espera superar a pobreza "e" as desigualdades sociais.

Assim, embora seja possível dizer que o PTC foi concebido oportunamente à luz de uma concepção multifacetada de desenvolvimento territorial, principalmente em função dos critérios adotados para a formação de um TC e das estratégias utilizadas nas políticas territoriais, é preciso ponderar que a noção de pobreza não parece ser entendida como algo que extrapola a esfera econômica. Isto é, mesmo que o programa busque atuar de forma mais ampla nos territórios, não há acordo entre a noção de pobreza utilizada e o grande número de estudos já realizados que compartilham o argumento de que a pobreza rural possui um carácter multidimensional (LEITE, 2013; MEDEIROS, 2012; BONNAL, 2013), uma vez que foi necessário acrescentar um novo termo para nomear as outras dimensões.

\section{A concepção de pobreza no território: analisando o PTDRS}

Neste tópico busca-se entender como é concebida a pobreza no Plano Territorial de Desenvolvimento Rural Sustentável (FLORES e PRESTES, 2010). De imediato, a primeira questão é sobre as poucas menções ao termo pobreza, que é utilizado três vezes. Na primeira, ainda na apresentação, trata-se da pobreza como reflexo da diminuição dos investimentos públicos a partir dos anos 1980. Na segunda, utiliza-se para enfatizar a relevância da qualidade de vida no desenvolvimento sustentável como contraponto aos círculos viciosos que originam a pobreza. $\mathrm{Na}$ terceira o termo é utilizado na apresentação de um mapa sobre a intensidade da pobreza no Rio Grande do Sul, com base na renda per capita, que é o critério adotado pelo Atlas do Desenvolvimento Humano (2010).

De modo geral, o plano dedica bastante espaço para discutir os eixos aglutinadores, os quais somam 17. Deste total, para fins de análise, considerou-se que 8 fazem parte de um grande eixo aqui chamado de "aspectos produtivos" geração de renda em diversas cadeias produtivas. Assim, o PTDRS apresenta os seguintes eixos: 1) autogestão territorial e organização social; 2) associativismo e cooperativismo; 3) assistência técnica e extensão rural/ATER; 4) gênero; 5) economia solidária; 6) indígenas; 7) educação no campo; 8) agroecologia; 9) gestão ambiental; e 10) aspectos produtivos.

\footnotetext{
${ }^{6} \mathrm{O}$ grande eixo "aspectos produtivos" inclui oito eixos: melhorias na matriz produtiva, agroindustrialização da produção agrícola familiar, organização da cadeia produtiva do leite, organização da cadeia da fruticultura, bioenergias, apicultura, crédito para agricultura familiar e questões tecnológicas de apoio às ações de produção no território.
} 
Apesar dessa diversidade de frentes de atuação, há outros aspectos que, em certa medida, não convergem com esta perspectiva, em princípio, multidimensional. Por exemplo, o objetivo geral do plano está alicerçado unicamente em melhorias na matriz produtiva (FLORES e PRESTES, 2010). Além disso, em uma discussão sobre as relações estabelecidas entre as entidades que compõem o arranjo organizacional do território, aborda-se a necessidade de solucionar graves problemas nacionais, como a desigualdade de renda e as desigualdades sociais, isto é, colocando as dinâmicas sociais numa esfera que não a da pobreza. Por fim, verificando os objetivos específicos ${ }^{7}$, à exceção do primeiro que aborda a autogestão, todos os demais estão alinhados com o foco na alteração da matriz produtiva.

Portanto, apesar da presença de diferentes eixos aglutinadores, que poderiam ser abrigados pela noção de desigualdade, a elaboração do PTDRS, a julgar pelo Plano de Desenvolvimento, colocou no centro das estratégias as intervenções com vistas a inclusão produtiva ou mudança da matriz produtiva. Essa discussão, amplamente abordada no PTDRS, refere-se à intensa utilização de sistemas de produção com baixa geração de renda por unidade de área, como gado de corte e grãos, por exemplo, que tendem a conduzir para uma situação de descapitalização em pequenas áreas, como é o caso de boa parte da agricultura familiar do território. Nesse momento da reflexão, convém um esclarecimento, a discussão levada a cabo nesse artigo de maneira alguma procura tecer quaisquer críticas às ações adotadas pelo território, pelo contrário, isso implicaria fazer uma análise de política pública, que, pela natureza coletiva da ação, não poderia ser realizada ser a presença do conjunto da sociedade civil que protagonizou o processo. Trata-se, na verdade, de um exercício de compreensão da concepção de pobreza adotada pela ação pública ao longo do seu transcurso.

Assim, reforça-se a discussão da seção anterior, a partir da qual a pobreza é entendida como um problema de renda e as demais esferas são contempladas pela dimensão social. Pensando desde essas duas esferas, o aspecto econômica parece ser protagonista, tendo em vista que o própria título do plano aborda essa questão: "melhoria na matriz produtiva agrícola regional" (FLORES e PRESTES, 2010). Nesse raciocínio, pode-se identificar uma lógica que reconhece as diferentes dimensões dos problemas regionais, mas que entende a renda como meio para que as demais desigualdades sejam superadas, sejam elas relacionadas à saúde, educação, alimentação, raça ou

\footnotetext{
${ }^{7}$ Objetivos específicos: Dinamização do território através da autogestão e revisão de acordos e parcerias; Contribuir com debate para buscar melhorias na matriz produtiva do território; Apoiar a dinamização do Associativismo e Cooperativismo no território; Dedicar apoio à agroindustrialização da produção da agricultura familiar para agregar valor e contribuir com a segurança alimentar; Organização e dinamização da cadeia produtiva do leite; Organização e dinamização da cadeia da fruticultura; Dinamização da cadeia produtiva das Bioenergias; Contribuir com a dinamização da produção da apicultura; Organização de um sistema de monitoramento e avaliação; Implantar centro de excelência tecnológica, em apoio à gestão, tecnologia da informação, análise e certificação da produção em todas suas etapas
} 
gênero. Essa noção em muito dialoga com a ideia defendida por Rocha (1995), que define pobreza como sendo o indivíduo sem recurso para adquirir seus bens básicos. Vale destacar que, por agora, é apenas algo normativo, que pode ou não se confirmar a partir da análise das ações efetivadas, que serão avaliadas no próximo tópico.

É de se destacar que o plano de desenvolvimento é, sobretudo, o momento em que o território, através de suas lideranças e representações, expressa suas necessidades e seus anseios. É, principalmente, nesse momento que a sociedade civil consegue dar ao programa sua cara, uma vez que, considerando as diretrizes gerais do PTC, elabora seu planejamento estratégico a partir de suas percepções e suas especificidades.

\section{Ações executadas: de qual pobreza estamos falando?}

Desde 2010, ano em que o TCMAU é instituído, até 2015, ano em que o relatório é publicado (MDA, 2015), houve um total de 58 ações $^{8}$. Nesta última data, as ações encontravam-se em cinco condições: i) concluídas (46,6\%); ii) não iniciadas (31\%); iii) paralisadas (17,2\%); iv) normais ${ }^{9}$ $(3,4 \%)$; e v) adiantadas (1,7\%). Para fins deste trabalho, considerou-se todas as ações registradas, independentemente de sua condição, uma vez que foram autorizadas e o objetivo é identificar seu perfil e não os resultados.

A começar pelo perfil das ações, cada uma delas foi classificada de acordo com os eixos aglutinadores propostos nos PTDRS, portanto, foram divididas em 10 eixos diferentes, lembrando que um dos eixos contempla todos aqueles que tinham relação direta com geração de renda ou inclusão produtiva. Das 58 ações executadas, 55 estão incluídas neste último eixo, aqui nomeados de "aspectos produtivos", enquanto as três ações restantes foram classificadas da seguinte maneira: uma no eixo "autogestão territorial e organização social", outra em "associativismos e cooperativismo" e, por fim, a última foi incluída no eixo "assistência técnica e extensão rural/ATER". Em termos de recursos investidos, isso significa $96 \%$ do valor destinado a questões produtivas, conforme tabela 1.

TABELA 1 - NÚMERO DE AÇÕES E VALORES DESTINADOS A CADA EIXO AGLUTINADOR PREVISTO NO PTDRS.

\begin{tabular}{clccc}
\hline \multirow{2}{*}{ Código } & Eixos aglutinadores & $\begin{array}{c}\text { Número } \\
\text { de ações }\end{array}$ & Valor (R\$) & $\begin{array}{c}\text { \% do } \\
\text { total }\end{array}$ \\
\hline 1 & Autogestão Territorial e Organização Social & 1 & $250.000,00$ & $2,23 \%$
\end{tabular}

\footnotetext{
${ }^{8}$ O relatório contempla todas as ações executadas desde a criação do território rural, em 2003, que somam 153. Todavia, como o foco do trabalho é justamente a discussão sobre pobreza, considerou-se apenas as ações registradas a partir de 2010 (58 ações).

${ }^{9}$ Trata-se das ações que se encontravam em curso e no período previsto.
} 


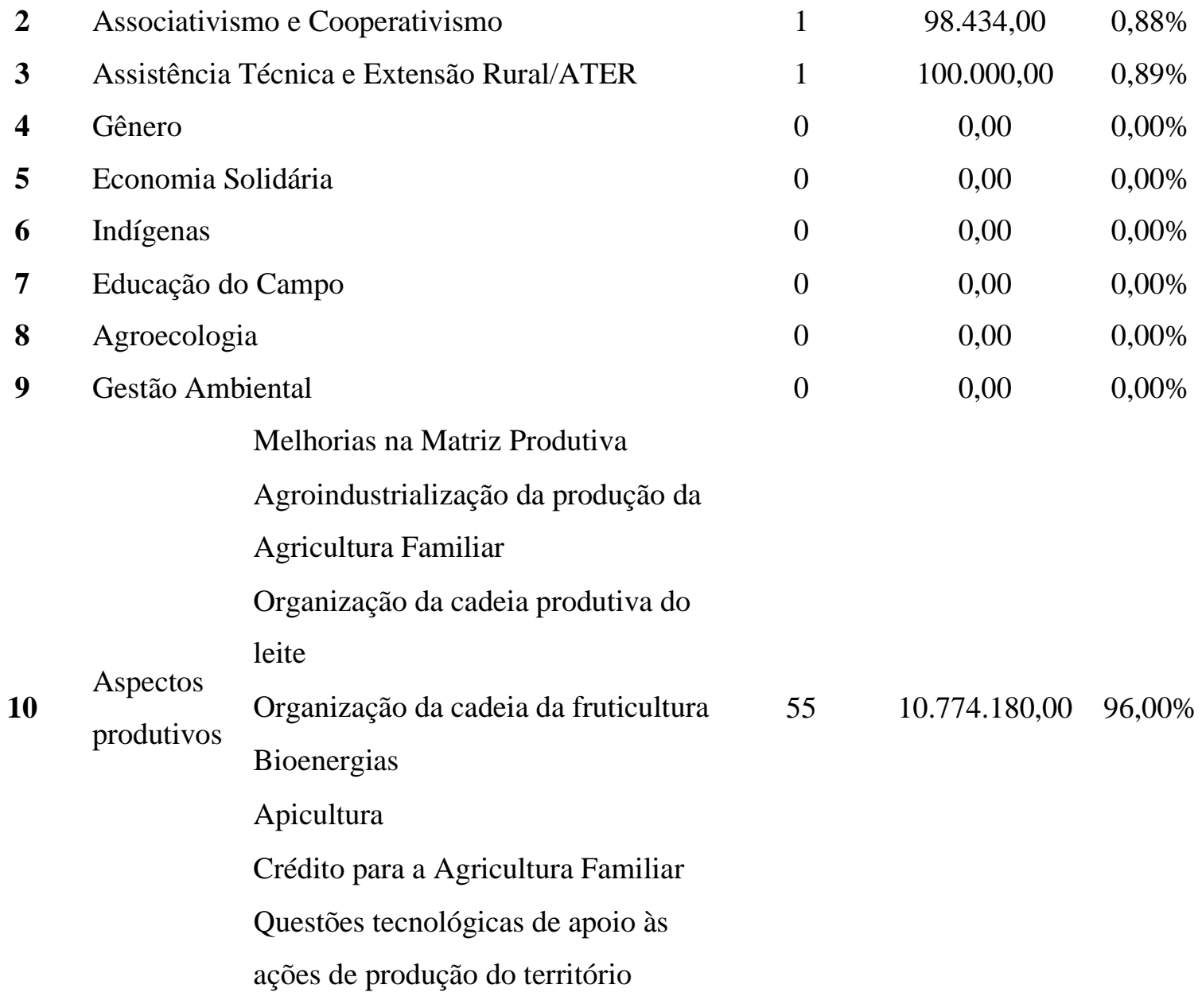

\begin{tabular}{cccc}
\hline Total & $\mathbf{5 8}$ & $11.222 .614,00$ & $\mathbf{1 0 0 \%}$ \\
\hline FONTE: elaborado pelo autor a partir de MDA (2015).
\end{tabular}

Esses dados evidenciam que nenhuma ação foi destinada especificamente para questões relacionadas à educação no campo, gênero, agroecologia, dentre outras. De imediato, percebe-se a noção de pobreza enquanto ausência de renda suficiente é hegemônica, sobretudo nesse momento final do programa, uma vez que as ações executadas foram majoritariamente direcionadas para o âmbito da esfera econômica, em detrimento das demais desigualdades.

Nesse sentido, os dados expressos na tabela 1 são suficientes para atender às demandas dos objetivos traçados e permitem-nos afirmar que as ações executadas tiverem como foco central a inclusão produtiva e o direcionamento de recursos para incentivar cadeias capazes de gerar maiores índices de renda. Pode-se dizer que a concepção preponderante de pobreza que foi identificada no decreto de criação do programa e no PTDRS se confirma através do perfil hegemônico de projetos executados no MAU (MDA, 2015). Certamente, trata-se de uma pobreza que é caracterizada pela dimensão da renda, cuja lógica parte do pressuposto que a escassez impossibilita o acesso às outras 
faces da pobreza. É como se a única forma de ter acesso à educação e saúde, por exemplo, passasse necessariamente pelo poder aquisitivo dos cidadãos, minimizando, inclusive, as atribuições do Estado nesse sentido. Assim, embora pareça existir certo acordo com relação a existência de várias dimensões da pobreza (BARROS et al., 2006), o consenso termina quando se discute como combater estes diferentes tipos de privações. Isto é, o acordo contempla apenas o fato de que pobreza é privação (MEDEIROS, 2012).

Na lógica identificada no TCMAU, pode-se, novamente, estabelecer uma relação muito próxima entre o perfil do programa neste território e a ideia de pobreza defendida por Rocha (1995; 1998), cuja perspectiva já foi abordada. Além disso, a tese defendida por Bonnal (2013) dialoga com a realidade aqui observada. Segundo Bonnal,

mesmo que o PTC possua um foco nos territórios de menor IDH, ele é, antes de tudo, um instrumento de dinamização do processo de desenvolvimento. Sendo assim, a redução da pobreza constitui apenas um ingrediente na estratégia de crescimento econômico territorial. Em ambos os casos, a atuação no combate à pobreza se dá de maneira indireta, mediante o efeito sistêmico das atividades desempenhadas em prol do desenvolvimento social e econômico e da dinamização da solidariedade entre os membros do público-alvo, limitado aos agricultores familiares (2013, p. 54).

A análise comparada dos dados, à título de demonstração, permite-nos ir além desta constatação e perceber as características dos principais municípios para os quais os recursos foram destinados. Essas características estão baseadas em dados referentes ao ano de 2010, isto é, ano em que os recursos do PTC começaram a ser executados. Dos quatro municípios que mais receberam recursos do PTC, três deles (Frederico Westphalen, Taquaruçu do Sul e Constantina) já possuíam, em 2010, os maiores valores de $\operatorname{IDHm}(0,76,0,74$ e 0,75, respectivamente), ou seja, essa é uma das esferas que parece não ter sido considerada como prioritária no momento de alocação dos recursos, uma vez que há uma série de município com índices consideravelmente menores para a dinâmica local, conforme Anexo 1.

A título de exemplo, Frederico Westphalen, que talvez seja o caso mais discrepante, recebeu $19 \%$ do total de recursos. É verdade que também se trata do município mais populoso do território, mesmo assim, não se pode desconsiderar que se trata de uma discrepância considerável, mesmo para um polo regional. Estas são apenas algumas considerações levantadas a partir de uma análise comparada dos dados de distribuição dos recursos, no entanto, um estudo mais detalhado sobre a alocação dos recursos nas diferentes condições municipais, realizado por meio de um teste de correlação entre variáveis, seria bastante pertinente para explorar essa questão. 
Esta discussão pode ser incrementada em outro momento por um estudo de análise de política pública, abordando especificamente os efeitos do programa e em que medida os objetivos foram cumpridos, o que está além de nossa pretensão. Por ora, ficou evidente o fato de que a pobreza no âmbito do TCMAU foi concebida como algo relacionado quase que exclusivamente à renda, embora o programa em si possua uma janela de possibilidades maior.

\section{Considerações Finais}

Neste trabalho buscou-se fazer uma análise da interpretação predominante de pobreza em cada uma das etapas do Programa Territórios da Cidadania no Médio Uruguai. Não se identificou mudanças importantes na concepção de pobreza desde a criação do programa até sua implementação. De acordo com os resultados desse artigo, a noção de pobreza sempre esteve relacionada à dimensão econômica, em desacordo com uma série de estudos que propõe um conceito mais amplo de pobreza. Não obstante, não se pode desconsiderar o fato de que foi necessário incluir uma nova expressão, a desigualdade social, para englobar outras dimensões que não a econômica. À medida que o PTC chega às suas fases finais a desigualdade de renda passa a ganhar mais força do que outras desigualdades, seja ela qual for, vide divisão de recursos para questões produtivas e outras. Isso ocorre por conta das mudanças que a política pública vai sofrendo ao longo de seu transcurso, principalmente a partir dos direcionamentos do território.

Sobre essa questão, convém mencionar que o percurso de uma ação do Estado não é retilíneo, isto é, mesmo que tudo aconteça conforme planejado e com a maior lisura possível, não necessariamente o perfil inicial de uma política pública se mantém desde sua formulação até a execução de fato, sobretudo quando se trata de uma ação pública que prevê aportes de representações de outras entidades, como a sociedade civil organizada, neste caso. Isso não significa, porém, que tornar a formulação das políticas permeável à sociedade seja um problema, pelo contrário, é a participação efetiva dos movimentos organizados que muito pode contribuir para que uma política pública seja executada em sintonia com o contexto e os anseios locais.

Evidencia-se, portanto, a complexidade de conceber pobreza como um objeto de estudo e, principalmente, como algo a ser combatido pelo Estado, uma vez que, para tal, é preciso estabelecer recortes, faixas e grupos prioritários e estas definições estão profundamente relacionadas às dimensões que são consideradas. Por fim, não se pode findar este trabalho sem mencionar a dificuldade de abordar tal problemática em uma conjuntura de intensa mudança político-institucional. Desde 2017, por exemplo, o programa não recebe mais recursos do governo federal, ou seja, está em 
stand-by. Parece não haver motivo de discutir a concepção de pobreza em um programa que praticamente inexiste, mesmo assim, é importante utilizar estas experiências para aprimorar a expertise sobre o Estado em ação, afinal de contas, já existiu no Brasil um amplo programa de fortalecimento de territórios rurais com foco nos mais pobres.

\section{Referências Bibliográficas}

Atlas Socioeconômico do Rio Grande do Sul/Rio Grande do Sul. Secretaria de Planejamento, Orçamento e Gestão. Departamento de Planejamento Governamental - 4.ed. - Porto Alegre: Secretaria de Planejamento, Orçamento e Gestão, 2019, 125p.

BANCO MUNDIAL, Relatório Anual 2018: investir em oportunidade, erradicar a pobreza. Washington: Banco Mundial, 2018.

BARROS, R. P.; CARVALHO, M. FRANCO, S. Pobreza multidimensional no Brasil. Texto para discussão - IPEA, Brasília, n. 1227, 2006.

BONNAL, P.; DELGADO, N.G.; CAZELLA, A.A. Subsídios metodológicos ao estudo do desenvolvimento territorial rural. In: DELGADO, N.; LEITE, S. (orgs.). Políticas públicas, atores sociais e desenvolvimento territorial no Brasil. Brasília: IICA, Série Desenvolvimento Rural Sustentável, Vol. 14, 2011, p. 35-60.

BONNAL, Referências e considerações para o estudo e a atuação dos programas de desenvolvimento territorial (PRONAT e PTC) na perspectiva da redução da pobreza em territórios rurais. In: LEITE, S. P. (Org.). Políticas de Desenvolvimento Territorial e Enfrentamento da Pobreza Rural no Brasil. Brasília: IICA, 2013.

BOSCARDIN, M. Reprodução social da agricultura familiar: uma análise demográfica em propriedades familiares sem sucessores no município de Frederico Westphalen, RS. 2017. Dissertação (Mestrado em Desenvolvimento Rural) - Programa de Pós-Graduação em Desenvolvimento Rural, Universidade Federal do Rio Grande do Sul, Porto Alegre, 2017.

BRASIL, DNN no 11.503, de 25 de fevereiro de 2008. Institui o Programa Territórios da Cidadania e dá outras providências, 2008.

DELGADO N. G.; LEITE, S. P. O Pronat e o PTC: possibilidades, limites e desafios das políticas territoriais para o desenvolvimento rural. In: GRISA, C.; SCHNEIDER, S. (org.). Políticas Públicas de Desenvolvimento Rural no Brasil. Porto Alegre: Editora da UFRGS, 2015.

DELGADO, G. C. Questão Agrária no Brasil: 1950-2003. In: JACCOUD, L. (Org.). Questão Social e Políticas Sociais no Brasil Contemporâneo. Brasília DF: IPEA, 2005.

FAVARETTO, A. Uma década de experimentações e o futuro das políticas de desenvolvimento territorial rural no Brasil. In: GRISA, C.; SCHNEIDER, S. (org.). Políticas Públicas de Desenvolvimento Rural no Brasil. Porto Alegre: Editora da UFRGS, 2015. 
FloRES, A. J.; PRESTES, R. M. Plano Territorial de Desenvolvimento Rural Sustentável PTDRS Território da Cidadania do Médio Alto Uruguai - RS: melhoria na matriz produtiva agrícola regional. Frederico Westphalen: URI, 2010.

FRANTZ, T. L.; SILVA NETO, B. A formação histórica dos sistemas agrários do Rio Grande do Sul. In: SILVA NETO B.; BASSO, D. (Org.). Sistemas agrários do Rio Grande do Sul: análise e recomendações de políticas, ed. 2, Ijuí: Unijuí, 2015.

FURTADO, Celso. Formação econômica do Brasil. 34 ed. São Paulo: Companhia das Letras, 2007.

GAZOLLA, M. Conhecimentos, produção de novidades e ações institucionais: cadeias curtas das agroindústrias familiares, 2012. Tese (Doutorado em Desenvolvimento Rural) - Programa de Pós-Graduação em Desenvolvimento Rural, Universidade Federal do Rio Grande do Sul, Porto Alegre, 2012.

GRISA, C. Projetos estratégicos e ações para o desenvolvimento territorial: uma análise do PRONAT e do programa Territórios da Cidadania. In: LEITE, S. P. (Org.). Políticas de Desenvolvimento Territorial e Enfrentamento da Pobreza Rural no Brasil. Brasília: IICA, 2013.

GRISA, C.; SCHNEIDER, S. (org.). Políticas Públicas de Desenvolvimento Rural no Brasil. Porto Alegre: Editora da UFRGS, 2015.

GUBERT, J. E.; LIMA, A. J. P.; TONIN, J.; PELEGRINI, G. Arranjo Produtivo Local Agroindústria Familiar e Diversidade do Médio Alto Uruguai - RS: Inovação em termos de desenvolvimento territorial. In: Third Internacional Conference Agriculture and Food in na Urbanizing Society. Anais..., Porto Alegre: UFRGS, 2018.

KAGEYAMA, A.; HOFFMANN, R. Pobreza no Brasil: uma perspectiva multidimensional. Economia e Sociedade, Campinas, v. 15, n.1, p. 79-112, 2006.

KUHN, D. D. et al. Pobreza no Rio Grande do Sul: a heterogeneidade revelada pela abordagem das capacitações nos municípios gaúchos. Revista Teoria e Evidência Econômica, v. 14, n. 26, p. 113134, mai/2006.

KUHN, D. Oportunidades, ruralidade e pobreza no Rio Grande do Sul: as relações apresentadas pela abordagem das capacitações nos municípios gaúchos, 2008. Tese (Doutorado em Desenvolvimento Rural) - Programa de Pós-Graduação em Desenvolvimento Rural, Universidade Federal do Rio Grande do Sul, Porto Alegre, 2008.

LEITE, S. P. Introdução. In: LEITE, S. P. (Org.). Políticas de Desenvolvimento Territorial e enfrentamento da pobreza rural no Brasil. Brasília: IICA, 2013.

LIMA et al. Dinâmica agrária e estratégias de desenvolvimento da agricultura: uma análise em termos de Sistemas Agrários no município de Pinheirinho do Vale - RS. Revista GEPEC, no prelo, 2020.

MALUFF, R. S. Elementos para uma agenda pública de enfrentamento à pobreza e inclusão socioprodutiva no meio rural na ótica do desenvolvimento territorial sustentável. In: LEITE, S. P. 
(Org.). Políticas de Desenvolvimento Territorial e enfrentamento da pobreza rural no Brasil. Brasília: IICA, 2013.

MATTEI, L.; TECCHIO, A. Caracterização e evolução da pobreza nos seis territórios da cidadania selecionados. In: LEITE, S. P. (Org.). Políticas de Desenvolvimento Territorial e enfrentamento da pobreza rural no Brasil. Brasília: IICA, 2013.

MEDEIROS, M. Medidas da desigualdade e pobreza. Brasília: Editora Universidade de Brasília. 2012, 172p.

MINISTÉRIO DO DENSENVOLVIMENO AGRÁRIO - MDA, Perfil Territorial: Médio Alto Uruguai - RS. Brasília: SDT/MDA, 2015, (Série Desenvolvimento Territorial).

OLCZEVSKI, Carlos Roberto. Dinâmica e perspectivas de desenvolvimento da agricultura do município de Pinheirinho do Vale/RS. 2007. Dissertação (Mestrado em Desenvolvimento, Gestão e Cidadania) UNIJUI, Ijuí, 2007.

PIKETTY, T. A economia da desigualdade. Rio de Janeiro: Editora Intrínseca, 2014, 119p.

ROCHA, S. Governabilidade e pobreza: o desafio dos números. Textos para discussão - IPEA, Brasília, n. 368, 1995.

ROCHA, S. Pobreza no Brasil: principais tendências da espacialização. Economia e Sociedade, Campinas, n. 10, p. 193-211, 1998.

RODRIGUES, C. G. Os “fetichistas" do Rio Grande do Sul sob a luz do progresso: a prática da Diretoria de Terras e Colonização. Revista de História Regional, v. 14, n. 1, 2009.

SEN, A. Desigualdade Reexaminada. Rio de Janeiro: Record, 2001.

SEN. A. Sobre Ética e Economia. São Paulo: Companhia das Letras, 1999.

SOARES, S. et al. A. Perfil da pobreza: Norte e Nordeste rurais. Brasília: IPEA, 2016.

TONIN, J. et al. Dinâmica Agrária e Fruticultura no Território Médio Alto Uruguai. In: Simpósio Latino-Americano de Estudos de Desenvolvimento Regional, 1, Ijuí. Anais... Ijuí: UNIJUÍ, 2018.

Artigo recebido em 08/04/2020. Aceito para publicação em 07/07/2020. 


\begin{tabular}{|c|c|c|c|c|c|c|c|c|}
\hline \multicolumn{9}{|c|}{$\begin{array}{c}\text { Anexo I } \\
\text { Território da Cidadania Médio Alto Uruguai }\end{array}$} \\
\hline Município & $\begin{array}{c}\text { Renda per } \\
\text { capita - } 2010 \\
(\mathbf{R} \$)\end{array}$ & $\begin{array}{c}\text { Índice de } \\
\text { gini - renda } \\
\text { (2010) }\end{array}$ & $\begin{array}{c}\text { Extremamente } \\
\text { pobres }(\%)\end{array}$ & $\begin{array}{c}\text { Vulneráveis } \\
\text { à pobreza } \\
(\%)\end{array}$ & $\begin{array}{l}\text { IDHm } \\
(2010)\end{array}$ & $\begin{array}{c}\text { Famílias } \\
\text { assentadas } \\
\qquad\left(\mathbf{n}^{\mathbf{o}}\right)\end{array}$ & $\begin{array}{c}\text { Área de } \\
\text { Reforma } \\
\text { Agrária (ha) }\end{array}$ & $\begin{array}{l}\text { Estabelecimentos da } \\
\qquad \mathrm{AF}\left(\mathbf{n}^{\mathbf{0}}\right)\end{array}$ \\
\hline Alpestre & 760,16 & 0,49 & 6,06 & 54,21 & 0,67 & 0 & 0 & 1734 \\
\hline Ametista do Sul & 499,77 & 0,58 & 5,58 & 48,31 & 0,68 & 0 & 0 & 919 \\
\hline Boa Vista das Missões & $1.196,56$ & 0,44 & 6,67 & 14,09 & 0,68 & 0 & 0 & 256 \\
\hline Caiçara & 659,58 & 0,47 & 2,57 & 51,47 & 0,70 & 0 & 0 & 937 \\
\hline Cerro Grande & 527,88 & 0,49 & 4,85 & 57,52 & 0,67 & 0 & 0 & 427 \\
\hline Constantina & 777,62 & 0,45 & 3,01 & 48,05 & 0,75 & 0 & 0 & 975 \\
\hline Cristal do Sul & 630,54 & 0,45 & 7,06 & 52,38 & 0,66 & 0 & 0 & 518 \\
\hline $\begin{array}{c}\text { Dois Irmãos das } \\
\text { Missões }\end{array}$ & 553,74 & 0,5 & 13,22 & 83,73 & 0,67 & 0 & 0 & 364 \\
\hline Engenho Velho & 539,00 & 0,55 & 16,45 & 54,05 & 0,72 & 0 & 0 & 218 \\
\hline Erval Seco & 677,58 & 0,52 & 10 & 65,31 & 0,69 & 19 & 202 & 1539 \\
\hline Frederico Westphalen & $1.021,84$ & 0,47 & 1,64 & 37,72 & 0,76 & 0 & 0 & 1275 \\
\hline $\begin{array}{c}\text { Gramado dos } \\
\text { Loureiros }\end{array}$ & 686,99 & 0,5 & 9,22 & 39,93 & 0,69 & 49 & 600 & 428 \\
\hline Iraí & $1.301,23$ & 0,54 & 10,3 & 32,74 & 0,69 & 0 & 0 & 819 \\
\hline Jaboticaba & $1.025,02$ & 0,53 & 18,1 & 13,58 & 0,66 & 0 & 0 & 806 \\
\hline Lajeado do Bugre & 771,47 & 0,49 & 16,13 & 43,65 & 0,61 & 0 & 0 & 610 \\
\hline
\end{tabular}




\begin{tabular}{|c|c|c|c|c|c|c|c|c|}
\hline Liberato Salzano & 559,67 & 0,43 & 3,37 & 52,72 & 0,69 & 0 & 0 & 1201 \\
\hline Nonoai & 974,79 & 0,5 & 5,21 & 45,86 & 0,70 & 0 & 0 & 704 \\
\hline Novo Tiradentes & 531,07 & 0,4 & 4,64 & 51,72 & 0,68 & 0 & 0 & 552 \\
\hline Novo Xingu & 548,05 & 0,41 & 0,38 & 66,07 & 0,77 & 0 & 0 & 430 \\
\hline Palmitinho & 715,29 & 0,42 & 5,66 & 52,89 & 0,72 & 0 & 0 & 1043 \\
\hline Pinhal & 523,52 & 0,45 & 3,28 & 45,52 & 0,72 & 0 & 0 & 307 \\
\hline Pinheirinho do Vale & 625,79 & 0,57 & 6,89 & 66,23 & 0,71 & 0 & 0 & 850 \\
\hline Planalto & 524,30 & 0,44 & 7,02 & 56,25 & 0,69 & 0 & 0 & 1294 \\
\hline Rio dos Índios & 660,14 & 0,49 & 8,97 & 53,34 & 0,66 & 0 & 0 & 970 \\
\hline Rodeio Bonito & 865,23 & 0,46 & 2,02 & 25,46 & 0,73 & 0 & 0 & 694 \\
\hline Sagrada Família & 643,97 & 0,54 & 7,28 & 50,93 & 0,68 & 0 & 0 & 612 \\
\hline São José das Missões & 853,60 & 0,43 & 4,65 & 27,3 & 0,65 & 0 & 0 & 746 \\
\hline São Pedro das Missões & 842,22 & 0,48 & 13,84 & 21,96 & 0,66 & 0 & 0 & 521 \\
\hline Seberi & $1.000,86$ & 0,52 & 7,46 & 42,35 & 0,72 & 0 & 0 & 1327 \\
\hline Taquaruçu do Sul & 786,91 & 0,53 & 2,56 & 37,07 & 0,74 & 0 & 0 & 461 \\
\hline Três Palmeiras & 489,32 & 0,61 & 7,05 & 55,33 & 0,70 & 0 & 0 & 693 \\
\hline Trindade do Sul & 823,33 & 0,49 & 8,47 & 38,35 & 0,69 & 47 & 600 & 733 \\
\hline Vicente Dutra & 707,05 & 0,5 & 10,34 & 37,24 & 0,64 & 0 & 0 & 102 \\
\hline Vista Alegre & $1.231,80$ & 0,57 & 5,87 & 26,5 & 0,74 & 0 & 0 & 437 \\
\hline Total & $25.535,89$ & - & - & - & - & 115 & 1402 & 25502 \\
\hline
\end{tabular}




\begin{tabular}{|c|c|c|c|c|c|c|c|c|c|}
\hline \multicolumn{10}{|c|}{ Território da Cidadania Médio Alto Uruguai } \\
\hline Município & $\begin{array}{c}\text { Pessoal } \\
\text { ocupado na } \\
\text { AF }\end{array}$ & $\begin{array}{l}\text { Técnicos de } \\
\operatorname{ATER}\left(n^{0}\right)\end{array}$ & $\begin{array}{c}\text { Crédito } \\
\text { fundiário }(\mathbf{R} \$)\end{array}$ & $\begin{array}{c}\text { Famílias } \\
\text { beneficiadas } \\
\text { PBF }\left(\mathbf{n}^{\circ}\right)\end{array}$ & $\begin{array}{c}\text { Famílias } \\
\text { beneficiadas } \\
\text { PBF }(\%)\end{array}$ & PAA $(\mathbf{R} \$)$ & PNAE (R\$) & $\begin{array}{c}\text { Ações TCMAU } \\
(\mathbf{R} \$)\end{array}$ & $\begin{array}{l}\% \text { do } \\
\text { total }\end{array}$ \\
\hline Alpestre & 4887 & 20 & $4.805 .488,00$ & 328 & $2 \%$ & $30.654,76$ & $26.970,97$ & $250.000,00$ & $2 \%$ \\
\hline Ametista do Sul & 2483 & 11 & $1.078 .770,00$ & 779 & $6 \%$ & 0,00 & $23.245,30$ & $670.000,00$ & $6 \%$ \\
\hline $\begin{array}{c}\text { Boa Vista das } \\
\text { Missões }\end{array}$ & 655 & 5 & $660.208,00$ & 119 & $1 \%$ & 0,00 & $6.611,77$ & 0,00 & $0 \%$ \\
\hline Caiçara & 2689 & 12 & $3.673 .245,00$ & 277 & $2 \%$ & 0,00 & 0,00 & 0,00 & $0 \%$ \\
\hline Cerro Grande & 1216 & 9 & $2.573 .436,00$ & 223 & $2 \%$ & 0,00 & $6.982,47$ & 0,00 & $0 \%$ \\
\hline Constantina & 2778 & 17 & $8.955 .195,00$ & 364 & $3 \%$ & 0,00 & $30.202,75$ & $714.934,00$ & $6,4 \%$ \\
\hline Cristal do Sul & 136 & 13 & $2.413 .354,00$ & 348 & $2 \%$ & 0,00 & $2.046,75$ & $350.000,00$ & $3 \%$ \\
\hline $\begin{array}{c}\text { Dois Irmãos das } \\
\text { Missões }\end{array}$ & 908 & 6 & $250.000,00$ & 184 & $1 \%$ & 0,00 & $11.275,11$ & $120.000,00$ & $1 \%$ \\
\hline Engenho Velho & 532 & 7 & $319.604,00$ & 146 & $1 \%$ & 0,00 & 0,00 & 0,00 & $0 \%$ \\
\hline Erval Seco & 455 & 13 & $5.506 .309,00$ & 755 & $5 \%$ & 0,00 & $24.610,40$ & $260.000,00$ & $2 \%$ \\
\hline $\begin{array}{c}\text { Frederico } \\
\text { Westphalen }\end{array}$ & 3801 & 18 & $4.761 .254,00$ & 1094 & $8 \%$ & 0,00 & $47.244,72$ & $2.147 .700,00$ & $19 \%$ \\
\hline $\begin{array}{c}\text { Gramado dos } \\
\text { Loureiros }\end{array}$ & 906 & 4 & $867.866,00$ & 257 & $2 \%$ & 0,00 & 0,00 & 0,00 & $0 \%$ \\
\hline Iraí & 2378 & 17 & $4.194 .650,00$ & 899 & $6 \%$ & 0,00 & 0,00 & $500.000,00$ & $4 \%$ \\
\hline
\end{tabular}




\begin{tabular}{|c|c|c|c|c|c|c|c|c|c|}
\hline Jaboticaba & 1956 & 9 & $5.348 .319,00$ & 538 & $4 \%$ & 0,00 & 0,00 & $104.370,00$ & $1 \%$ \\
\hline $\begin{array}{c}\text { Lajeado do } \\
\text { Bugre }\end{array}$ & 1541 & 9 & $1.452 .610,00$ & 239 & $2 \%$ & 0,00 & $7.507,30$ & $100.000,00$ & $1 \%$ \\
\hline $\begin{array}{l}\text { Liberato } \\
\text { Salzano }\end{array}$ & 3498 & 17 & $6.030 .564,99$ & 419 & $3 \%$ & 0,00 & 0,00 & $854.810,00$ & $8 \%$ \\
\hline Nonoai & 2 & 11 & $1.865 .303,00$ & 956 & $7 \%$ & 0,00 & $35.218,20$ & 0,00 & $0 \%$ \\
\hline Novo Tiradentes & 1534 & 10 & $3.025 .835,00$ & 182 & $1 \%$ & 0,00 & 0,00 & 0,00 & $0 \%$ \\
\hline Novo Xingu & 1247 & 6 & $3.383 .615,00$ & 45 & $0 \%$ & 0,00 & $11.156,45$ & 0,00 & $0 \%$ \\
\hline Palmitinho & 3143 & 11 & $3.376 .309,48$ & 520 & $4 \%$ & 0,00 & 0,00 & $350.000,00$ & $3 \%$ \\
\hline Pinhal & 903 & 9 & $2.192 .912,00$ & 141 & $1 \%$ & 0,00 & $4.671,89$ & $230.000,00$ & $2 \%$ \\
\hline $\begin{array}{c}\text { Pinheirinho do } \\
\text { Vale }\end{array}$ & 2683 & 9 & $2.620 .414,80$ & 389 & $3 \%$ & 0,00 & $14.982,99$ & $110.000,00$ & $1 \%$ \\
\hline Planalto & 3776 & 17 & $8.490 .361,50$ & 886 & $6 \%$ & 0,00 & $24.669,78$ & $350.000,00$ & $3 \%$ \\
\hline Rio dos Índios & 2494 & 6 & $663.163,87$ & 380 & $3 \%$ & 0,00 & $16.776,74$ & $198.000,00$ & $2 \%$ \\
\hline Rodeio Bonito & 161 & 7 & $4.034 .071,00$ & 314 & $2 \%$ & 0,00 & $18.256,40$ & $752.800,00$ & $7 \%$ \\
\hline Sagrada Família & 1757 & 9 & $1.695 .000,00$ & 223 & $2 \%$ & $287.340,00$ & 0,00 & $290.000,00$ & $3 \%$ \\
\hline $\begin{array}{c}\text { São José das } \\
\text { Missões }\end{array}$ & 1861 & 10 & $3.733 .305,25$ & 269 & $2 \%$ & $1.100,00$ & $5.212,05$ & $200.000,00$ & $2 \%$ \\
\hline $\begin{array}{c}\text { São Pedro das } \\
\text { Missões }\end{array}$ & 1176 & 5 & $806.644,36$ & 174 & $1 \%$ & 0,00 & 0,00 & 0,00 & $0 \%$ \\
\hline Seberi & 3513 & 16 & $8.865 .871,00$ & 1029 & $7 \%$ & 0,00 & $18.108,20$ & $200.000,00$ & $2 \%$ \\
\hline
\end{tabular}




\begin{tabular}{|c|c|c|c|c|c|c|c|c|c|}
\hline $\begin{array}{c}\text { Taquaruçu do } \\
\text { Sul }\end{array}$ & 1444 & 8 & $900.698,00$ & 98 & $1 \%$ & 0,00 & 0,00 & $1.420 .000,00$ & $13 \%$ \\
\hline Três Palmeiras & 1719 & 12 & $3.970 .150,00$ & 327 & $2 \%$ & 0,00 & $9.227,92$ & $100.000,00$ & $1 \%$ \\
\hline Trindade do Sul & 1801 & 10 & $3.565 .655,00$ & 578 & $4 \%$ & 0,00 & $19.015,54$ & $500.000,00$ & $4 \%$ \\
\hline Vicente Dutra & 2907 & 9 & $1.325 .802,92$ & 375 & $3 \%$ & 0,00 & $7.126,07$ & 0,00 & $0 \%$ \\
\hline Vista Alegre & 1148 & 14 & $1.573 .080,00$ & 134 & $1 \%$ & 0,00 & 0,00 & $450.000,00$ & $4 \%$ \\
\hline Total & 64088 & 366 & $108.979 .065,17$ & 13989 & - & $319.094,76$ & $371.119,77$ & $11.222 .614,00$ & $100 \%$ \\
\hline
\end{tabular}

